\title{
Adenocarcinoma of the cervical esophagus arising within a long segment of Barrett's metaplasia
}

A 53-year-old man was referred to the endoscopy unit for evaluation of noncardiac chest pain. He did not report dysphagia, gastroesophageal reflux disease symptoms, or weight loss. His medical record included hyperlipidemia and duodenal peptic ulcer disease along with a history of smoking (20 pack-years). Upper endoscopy showed a long segment of columnar-type epithelium extending from the top of the gastric folds ( $35 \mathrm{~cm}$ from incisors) ( $\mathbf{F i g .} \mathbf{1}$ a) to the cervical esophagus $(20 \mathrm{~cm})$, corresponding to $\mathrm{C} 15 \mathrm{M} 15$ (Prague classification) Barrett's esophagus (BE). The distal and middle part of the $B E$ segment was inconspicuous both in white-light and narrow-band imaging ( Fig.1 b). However, at the top of the Barrett's metaplasia, just below the upper esophageal sphincter, a protruded ulcerated tumor was identified ( $\triangleright \mathbf{F i g . 1} \mathbf{c}$, - Video 1). Tumor biopsies confirmed a well-differentiated adenocarcinoma on a background of intestinal metaplasia. Positron emission tomography-computed tomography scan showed a marked increase in metabolic activity in the cervical esophagus without evidence of metastatic spread ( $\triangleright$ Fig. 1 d).

Although squamous cell carcinoma (SCC) accounts for nearly $90 \%$ of esophageal cancers worldwide, the incidence of esophageal adenocarcinoma (EAC) has already surpassed that of SCC in several regions of North America and Europe [1]. Similarly to its precursor condition, BE, EAC is typically located in the distal esophagus where inflammation from gastric acid reflux is most profound. Carcinoma of the cervical esophagus is rare ( $2 \%-10 \%)$ and nearly all of these tumors are SCC in origin ( 95\%) [2]. Reports of adenocarcinomas in this region are confined to cases arising within inlet patches $[3,4]$, rather than $B E$. While neoplastic changes preferentially occur in the proximal parts of BE segments [5], the extension of Barrett's metaplasia rarely reaches
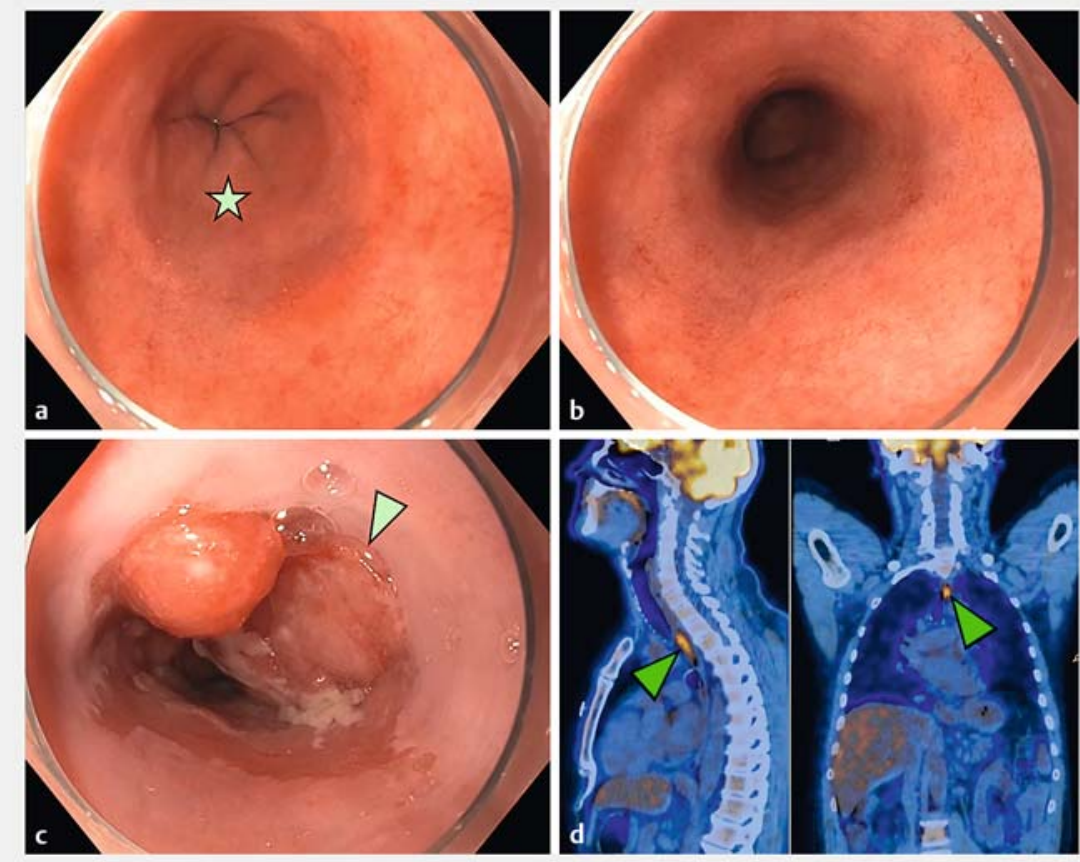

- Fig. 1 Images at presentation. a Distal esophagus and the top of the gastric folds at $35 \mathrm{~cm}$ from the incisors (star). $\mathbf{b}$ The middle part of the Barrett's esophagus segment without visible abnormalities on white-light imaging. $\mathbf{c}$ Top of the Barrett segment with a protruded and partially ulcerated tumor at $20 \mathrm{~cm}$ from the incisors; the border between columnar and squamous epithelium (Z-line) is clearly visible (arrowhead). $\mathbf{d}$ Positron emission tomographycomputed tomography showing a marked increase in metabolic activity in the cervical esophagus (sagittal and coronal planes).

the cervical esophagus. The optimal management of such tumors is not established; however, surgery remains the mainstay treatment for adenocarcinoma. In our case, a multidisciplinary decision for pharyngo-laryngo-esophagectomy with neoadjuvant chemoradiotherapy was taken.

Endoscopy_UCTN_Code_CCL_1AB_2AC_3AB

\section{Competing interests}

The authors declare that they have no conflict of interest.
The authors

Wladyslaw Januszewicz ${ }^{1,2}$, Krzysztof Trzebinski ${ }^{1}$, Malgorzata Lenarcik ${ }^{3}$,

Anna Cencelewicz-Lesikow ${ }^{1}$, Michal F. Kaminski ${ }^{1,2,4}$, Jaroslaw Regula', ${ }^{1,2}$

1 Department of Gastroenterology, Hepatology and Clinical Oncology, Medical Centre for Postgraduate Education, Warsaw, Poland

2 Department of Oncological Gastroenterology, The Maria SklodowskaCurie National Research Institute of Oncology, Warsaw, Poland 


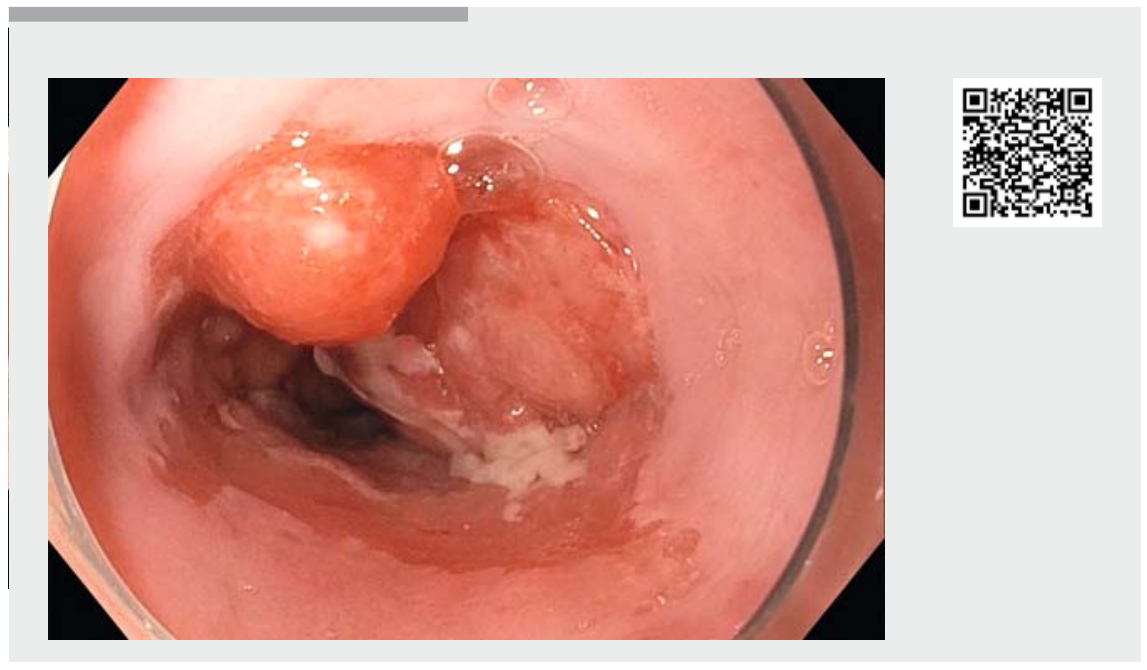

Video 1 High-definition white-light endoscopy showing the whole length of the esophagus, from the gastroesophageal junction and along the long segment of Barrett's esophagus to the proximal esophagus, where a protruded, partially ulcerated tumor was identified at $20 \mathrm{~cm}$ from the incisors. Narrow-band imaging helped to delineate the lesion.

3 Department of Pathology and Diagnostic Laboratory, The Maria Sklodowska-Curie National Research Institute of Oncology, Warsaw, Poland

4 Institute of Health and Society, University of Oslo, Oslo, Norway

\section{Corresponding author}

\section{Wladyslaw Januszewicz, MD}

Department of Gastroenterology, Hepatology and Clinical Oncology, Medical Centre for Postgraduate Education, W.K. Roentgen 5 street, 02-781 Warsaw, Poland

Fax: +48-22-5463035

wjanuszewicz@coi.pl
Bibliography

Endoscopy 2021; 53: E112-E113

DOI 10.1055/a-1207-0455

ISSN 0013-726X

published online 15.7.2020

(C) 2020. Thieme. All rights reserved.

Georg Thieme Verlag KG, Rüdigerstraße 14, 70469 Stuttgart, Germany

\section{ENDOSCOPY E-VIDEOS}

https://eref.thieme.de/e-videos

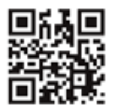

Endoscopy E-Videos is a free access online section, reporting on interesting cases and new techniques in gastroenterological endoscopy. All papers include a high quality video and all contributions are freely accessible online.

This section has its own submission website at https://mc.manuscriptcentral.com/e-videos
[1] Rustgi AK, El-Serag HB. Esophageal Carcinoma. N Engl J Med 2014; 371: 2499-2509

[2] Hoeben A, Polak J, Van De Voorde L et al. Cervical esophageal cancer: a gap in cancer knowledge. Ann Oncol 2016; 27: 16641674

[3] Probst A, Schaller T, Messmann H. Adenocarcinoma arising from ectopic gastric mucosa in an esophageal inlet patch: treatment by endoscopic submucosal dissection. Endoscopy 2015; 47: 337-338

[4] Ajmal S, Young JS, $\mathrm{Ng} \mathrm{T}$. Adenocarcinoma arising from cervical esophageal gastric inlet patch. J Thorac Cardiovasc Surg 2015; 149 : 1664-1665

[5] Cotton CC, Duits LC, Wolf WA et al. Spatial predisposition of dysplasia in Barrett's esophagus segments: a pooled analysis of the SURF and AIM dysplasia trials. Am J Gastroenterol 2015; 110: 1412-1419 